\title{
Olanzapine and sibutramine have opposing effects on the motivation for palatable food
}

\author{
Esther M. van der Zwaal ${ }^{\mathrm{a}}$, Sanna K. Janhunen ${ }^{\mathrm{a}}$, Mieneke C.M. Luijendijk ${ }^{\mathrm{a}}$, \\ Roxana Baclesanu ${ }^{a}$, Louk J.M.J. Vanderschuren ${ }^{a, b}$, Roger A.H. Adan ${ }^{a, *}$ \\ and Susanne E. La Fleur ${ }^{\mathrm{a}, \mathrm{c}, *}$
}

Both olanzapine and sibutramine target serotonergic and noradrenergic neurotransmission and influence body weight, but in opposite ways. The second-generation antipsychotic olanzapine, an antagonist at serotonergic and noradrenergic receptors, frequently induces weight gain as a side-effect, whereas sibutramine, a noradrenaline/serotonin reuptake inhibitor, is known as a weight-reducing agent. To investigate whether altered motivation for palatable food influences the effect of these drugs on body weight, we determined their effects on responding for sucrose pellets under a progressive ratio schedule of reinforcement in rats. We found that a low dose of olanzapine selectively increased responding to sucrose, without affecting free-feeding intake of sucrose.

In contrast, sibutramine dose-dependently reduced responding to sucrose and similarly reduced free-feeding intake. Furthermore, coadministration of a dose of sibutramine that failed to affect responding to sucrose when administered alone prevented the increase in motivation by the effective dose of olanzapine. These data show that increased motivation for palatable food is likely to be a significant contributor to olanzapine-induced weight gain. Moreover, the ability of sibutramine to reduce this motivation for palatable food may play an important role in the efficacy of sibutramine as an add-on treatment to counteract olanzapine-induced weight gain. Behavioural Pharmacology 00:000-000 (c) 2012 Wolters Kluwer Health | Lippincott Williams \& Wilkins.

Behavioural Pharmacology 2012, 00:000-000

Keywords: food-motivated behavior, noradrenaline, olanzapine, palatable food, progressive ratio of reinforcement, serotonin, sibutramine, sucrose

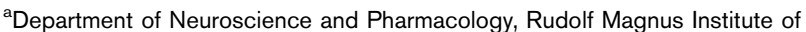
Neuroscience, University Medical Center Utrecht, bepartment of Animals in Science and Society, Division of Behavioural Neuroscience, Faculty of Veterinary Medicine, Utrecht University, Utrecht, The Netherlands and ${ }^{\mathrm{C}}$ Department of Endocrinology and Metabolism, Academic Medical Center, University of Amsterdam, Amsterdam, The Netherlands

Correspondence to Dr Susanne E. La Fleur, PhD, Department of Endocrinology and Metabolism, Academic Medical Center, University of Amsterdam, Meibergdreef 9, F5-165, 1105 AZ, The Netherlands

E-mail: s.e.lafleur@amc.uva.nl

* Roger A.H. Adan and Susanne E. La Fleur contributed equally to the writing of this article.

Present address Sanna K. Janhunen: CNS Research, Research and Development, Orion Corporation, Orion Pharma, Turku, Finland.

Received 24 May 2011 Accepted as revised 20 December 2011

\section{Introduction}

Weight alterations are frequently observed with psychoactive drugs that target the serotonin (5-HT) and noradrenaline (NA) system (Malone, 2005). Olanzapine and sibutramine are two examples that show opposite effects on body weight.

Olanzapine is a second-generation antipsychotic drug, that is an antagonist at 5-HT and alpha-adrenergic receptors, as well as at several other receptors (Bymaster et al., 1999). It is considered to be one of the most effective drugs on the market today for the treatment of schizophrenia and bipolar disorder (Scherk et al., 2007; Smith et al., 2007; Leucht et al., 2009a, 2009b). Unfortunately, similar to other second-generation antipsychotics, the significant weight gain that frequently occurs as a side-effect is a major cause for concern (Parsons et al., 2009). The exact mechanisms underlying olanzapine-induced weight gain remain unclear, but clinical reports suggest that altered eating behavior is a major component. Patients using second-generation antipsychotics frequently report an increase in appetite
(Basson et al., 2001; Costa e Silva et al., 2001; Eder et al., 2001; Kluge et al., 2007) and seem more susceptible to hunger (Blouin et al., 2008). Furthermore, it has been suggested that second-generation antipsychotics may induce craving for palatable foods and sugary drinks (Bromel et al., 1998; Kluge et al., 2007), with similar effects observed in certain animal studies (Cilia et al., 2001; Zhang et al., 2005b; Galistu et al., 2011). Increased desire for high-calorie foods can have a marked impact on total caloric intake of patients and could therefore be an important contributing factor to antipsychotic-induced weight gain, although appropriate clinical studies are lacking to confirm this.

Sibutramine inhibits the reuptake of 5-HT, NA and, at higher doses, also of dopamine. Although it was originally designed as an antidepressant, it has mainly been used as a weight-loss drug (Luque and Rey, 2002). It is one of the drugs that has been successfully used as add-on treatment to counteract antipsychotic-induced weight gain in clinical trials (Henderson et al., 2005; McElroy et al., 2007). The 
mechanisms responsible for the attenuation of antipsychotic-induced weight gain by sibutramine are not entirely clear. However, a recent meta-analysis indicated that, in studies investigating the effects of mitigating agents on olanzapine-induced weight gain, predictors of weight loss were reductions in appetite, hunger, and craving for carbohydrates (Stauffer et al., 2009). Indeed, sibutramine has been shown to reduce hunger and food intake in both humans and rodent models. However, to our knowledge it has not been investigated whether sibutramine also affects motivation for palatable food, independent of its effects on hunger or satiety (Jackson et al., 1997; Grignaschi et al., 1999; Chapelot et al., 2000; Halford et al., 2010).

On the basis of these clinical findings, we hypothesized that olanzapine increases the motivation for palatable food, whereas sibutramine reduces it. Second, we hypothesized that, when both drugs are coadministered, sibutramine attenuates the effect of olanzapine and that this mechanism plays a role in the efficacy of this drug to reduce olanzapine-induced weight gain. Moreover, as sibutramine acts as a reuptake inhibitor for NA and 5-HT, an interaction effect would suggest that NA and/or 5-HT receptors are involved in the effects of olanzapine on the motivation for palatable food.

To test these hypotheses, we first determined the effects of sibutramine and olanzapine on the motivation for palatable food in a rat model, using a progressive ratio (PR) schedule of reinforcement (Hodos, 1961; Richardson and Roberts, 1996; La Fleur et al., 2007). Next, we examined the effect of combined administration of olanzapine and sibutramine. To further characterize the effects observed under the PR schedule, we also determined the effects of olanzapine and sibutramine in a 'free-feeding' paradigm in which rats no longer needed to work to obtain their food reward, but had free access to sucrose pellets for a limited time each day. Although the effects of antipsychotics on body weight appear more pronounced in female than in male rats (Boyda et al., 2010), we preferred to use male rats, because feeding behavior in female rats is subject to larger variability because of their estrous cycle (Ter Haar, 1972; Blaustein and Wade, 1976).

\section{Methods \\ Subjects}

Male Wistar rats, weighing 275-300 g, were purchased from Charles River Laboratories (Crl-Wu, Sulzfeld, Germany). They were individually housed in a temperature and humidity-controlled room $\left(21 \pm 2^{\circ} \mathrm{C}\right)$ under a reversed $12 \mathrm{~h} / 12 \mathrm{~h}$ light/dark cycle (lights on at 19:00 h). In their home cage, rats had free access to water and standard laboratory chow [CRM(E), Special Diet Services, Witham, Essex, UK] throughout the experiment to ensure that responding for palatable food was not affected by food restriction. Each experiment was performed in the dark phase, when rats are normally active and eat the most. All experimental procedures were approved by the Committee for Animal Experimentation of Utrecht University and were conducted in agreement with Dutch laws (Wet op de Dierproeven, 1996) and European regulations (Guideline 86/609/EEC).

\section{Training}

\section{Operant conditioning}

To assess effects on the motivation to work for palatable food, rats were trained to lever-press for sucrose pellets under a PR schedule of reinforcement. We used 12 operant conditioning chambers designed for rats $(30.5 \times 24.2 \times$ $21.0 \mathrm{~cm}$; Med Associates, Georgia, Vermont, USA). Each chamber had a metal grid floor and was equipped with two retractable levers with white cue lights above them and a food pellet dispenser that could deliver $45 \mathrm{mg}$ pellets (Noyes precision sucrose pellets, formula F, Research Diets, New Brunswick, New Jersey, USA) to a food tray. All chambers were contained in sound-attenuated and ventilated cabinets and were illuminated during sessions by a white house light. Data collection and processing was controlled by MED-PC software (Med Associates, Med Associates, Georgia, Vermont, USA).

Five days after arrival, training of rats was initiated with a shaping procedure, followed by seven sessions under a fixed ratio 1 schedule, with two sessions per day and allowing at least $3 \mathrm{~h}$ between sessions. During shaping, rats were placed in the operant cage for $60 \mathrm{~min}$. Every minute the cue light above the active lever was switched on and a sucrose pellet was delivered. During fixed ratio sessions, each press on the active lever resulted in the delivery of one sucrose pellet, illumination of the cue light, and retraction of both levers. Twenty seconds after delivery of the pellet, the cue light was switched off and the levers were reinserted into the chamber. Responding on the inactive lever was recorded, but had no programmed consequences. Sessions lasted $30 \mathrm{~min}$ or until rats earned 60 rewards. Next, rats were switched to a PR schedule with one session a day. Under a PR schedule, the cost of a reward is progressively increased over successive trials to determine the amount of work the rat is willing to perform to acquire it. The response requirement for each reward increased as follows (Roberts and Bennett, 1993; Richardson and Roberts, 1996): response $=$ formula $\left(5 \times \mathrm{e}^{0.2 \times \text { reward number }}\right)-5$, resulting in the following series: 1 , 2, 4, 6, 9, 12, 15, 20, 25, 32, 40, 50, 62, 77, 95, 118, 145, 178, $219,268,328,402,603,737$, etc. Each session ended when the rat failed to earn a reward within $60 \mathrm{~min}$. The number of rewards earned at the end of the session was termed 'breakpoint', which can be interpreted as a measure of the motivational value of the reward. Responding was considered stable when the number of earned sucrose pellets did not differ more than $20 \%$ for three sessions. Most rats stabilized within five to 10 sessions; therefore, we proceeded with injections after 2 weeks of training. At this point, the ratio of inactive to active lever presses was $\sim 1.6 \%$ on average $(\sim 4.5$ lever presses per session), indicating that rats had learned to respond specifically on the active lever. 


\section{Free feeding}

This paradigm was used to test the effects of drug administration on intake of freely available sucrose. Rats were placed in test cages for $60 \mathrm{~min}$ each day. These cages were identical to the home cage but contained only bedding and a hopper filled with sucrose pellets (identical to those used for operant conditioning). Food hoppers were weighed before and after each session to quantify sucrose intake. After 2 weeks of training, we proceeded with drug administration.

\section{Experiment 1: effects on operant responding for sucrose pellets}

For this experiment, a total of 36 rats were trained in operant cages to respond for sucrose pellets under a PR schedule of reinforcement. The experiment was performed in two runs: the first group of 12 rats received olanzapine injections only, the second group of 24 rats also received sibutramine injections. Rats were given an intraperitoneal (i.p.) injection of saline $30 \mathrm{~min}$ before training on two separate days to habituate them to i.p. injections. Next, all rats $(n=36)$ received three injections of olanzapine $(0.1,0.3$, and $1 \mathrm{mg} / \mathrm{kg})$ and a saline injection (according to a Latin square design), serving as their own control (experiment 1A).

After determining the dose-response curve for olanzapine, the 24 rats of the second experimental run received injections of sibutramine $(0.1,0.3$, and $1 \mathrm{mg} / \mathrm{kg})$ and saline according to a Latin square design (experiment $1 \mathrm{~B}$ ).

On the basis of the results of experiment $1 \mathrm{~A}$ and $1 \mathrm{~B}$, we chose to test the effect of combined administration of the effective dose of olanzapine, which significantly increased breakpoint $(0.1 \mathrm{mg} / \mathrm{kg})$, and the subeffective dose of sibutramine, that is, the highest dose that did not affect breakpoint $(0.3 \mathrm{mg} / \mathrm{kg})$. Therefore, the same rats $(n=24)$ received an injection of olanzapine followed by sibutramine and, as a control, saline followed by saline (experiment $1 \mathrm{C}$ ).

\section{Experiment 2: effects on operant responding for fat-enriched pellets}

To investigate whether the effect of olanzapine might be more pronounced on operant responding for fatty palatable food, an additional pilot experiment was performed in which we determined the dose-response curve for olanzapine using a method identical to that of experiment $1 \mathrm{~A}$ but using 12 rats that had to lever-press for fat-enriched pellets (13.7\% fat; Omni Treat tab, Richmond Indiana, USA) instead of sucrose pellets.

\section{Experiment 3: effects on free-feeding intake of sucrose pellets}

For this experiment, 24 naïve rats were trained in the freefeeding paradigm. Rats received a saline injection (i.p.) $30 \mathrm{~min}$ before access to the sucrose pellets on two separate days to habituate animals to the i.p. injection procedure. Next, each rat received injections of olanzapine $(0.03,0.1$, and $0.3 \mathrm{mg} / \mathrm{kg}$ ) and a saline injection according to a Latin square design (experiment $3 \mathrm{~A}$ ). Finally, each rat received injections of sibutramine $(0.1,0.3$, and $1 \mathrm{mg} / \mathrm{kg})$ and saline according to a Latin square design (experiment $3 \mathrm{~B}$ ).

\section{Drugs}

Olanzapine (Chempacific Corp., Baltimore, Maryland, USA) was dissolved in a minimum quantity of $1 \mathrm{~mol} / \mathrm{l}$ hydrochloric acid and diluted with saline, after which $\mathrm{pH}$ was set to $\sim 5.5$ with $1 \mathrm{~mol} / \mathrm{l} \mathrm{NaOH}$. The obtained stock solution of $3 \mathrm{mg} / \mathrm{ml}$ was aliquoted and stored at $-20^{\circ} \mathrm{C}$. On injection days, aliquots were defrosted and diluted to the required concentrations. The highest dose of olanzapine $(1 \mathrm{mg} / \mathrm{kg})$ was chosen on the basis of a pilot experiment that revealed a marked reduction in operant responding at a dose of $3 \mathrm{mg} / \mathrm{kg}$, most likely because of sedation. All injections of olanzapine were administered i.p. $1 \mathrm{~h}$ before testing, with a minimum of 3 days between injections.

Sibutramine hydrochloride (Tocris Bioscience, Bristol, England, UK) was dissolved in slightly warmed saline to obtain a solution of $1 \mathrm{mg} / \mathrm{ml}$ (calculated as base), which was further diluted with saline as necessary. Because we were interested in determining the effects of sibutramine that were independent of its effects on hunger and satiety, the highest dose was chosen on the basis of previous experiments in our laboratory that revealed significant effects on total food intake only at doses of $3 \mathrm{mg} / \mathrm{kg}$ or higher. All injections of sibutramine were administered $30 \mathrm{~min}$ before testing (i.p.) with a maximum of one injection per week. All injection volumes were $1 \mathrm{ml} / \mathrm{kg}$, and a washout period of at least 1 week was included after each dose-response curve experiment.

\section{Data analysis}

All data are presented as mean values \pm SEM. Effects on PR performance (breakpoint) are presented as the number of rewards obtained in the session after each injection. Effects on free-feeding intake are presented as change in sucrose intake compared with control injection. Statistical analysis was performed using SPSS software (version 15.0 for Windows, SPSS Inc., Chicago, Illinois, USA). Because the data were not normally distributed, nonparametric tests were used. Data from each experiment were first analyzed by Friedman's analysis of variance. Where appropriate, this was followed by a two-tailed Wilcoxon signed rank test between each treatment condition versus the control condition. Findings were considered as statistically significant if $P$ value was less than 0.05 .

\section{Results Experiment 1}

Olanzapine significantly affected breakpoint (the number of rewards obtained) in experiment 1 A [Fig. $1 ; \chi^{2}(3)=9.9$, $P=0.018]$. Post-hoc tests revealed that this was due to the effect of the lowest dose of $0.1 \mathrm{mg} / \mathrm{kg}$, which caused a significant increase in breakpoint to work for sucrose 
Fig. 1

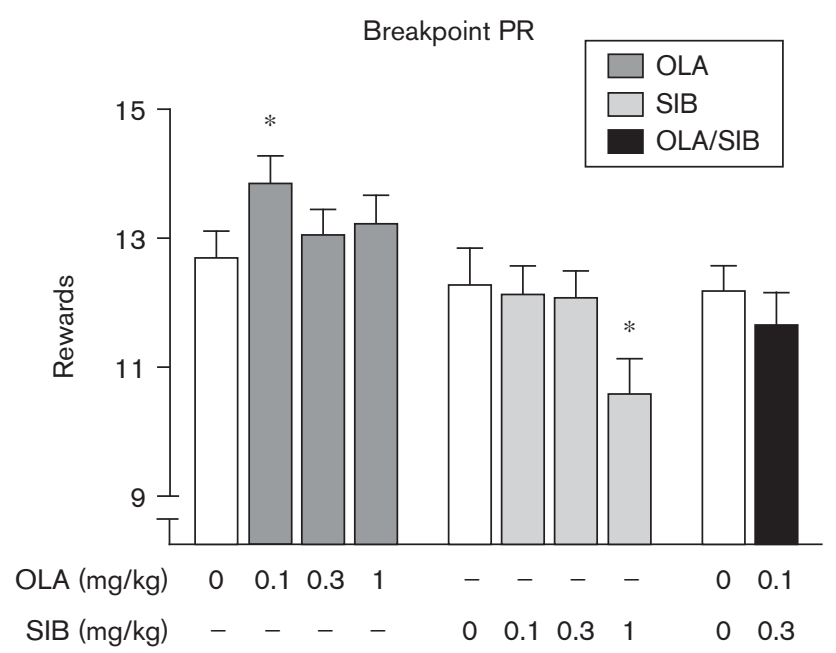

Effects of administration of olanzapine (OLA) and sibutramine (SIB), alone or in combination, on operant responding for sucrose pellets under a progressive ratio schedule of reinforcement in experiment 1 . Data are expressed as mean ( \pm SEM) number of rewards earned at the end of the test sessions. $* P$ less than 0.05 versus saline injection.

pellets $(Z=-2.90, \quad P=0.002)$. At higher doses, this effect was no longer significant (Fig. 1). In both of the experimental runs the largest increase in breakpoint was observed at the lowest dose of olanzapine administered; thus, we could not exclude effects occurring at even lower doses. However, after completing the first dose-response experiment $(1 \mathrm{~A})$, we additionally tested the dose of $0.03 \mathrm{mg} / \mathrm{kg}$ of olanzapine against saline injection $(n=24)$; this dose had no effect on breakpoint for sucrose pellets (data not shown), indicating that the $0.1 \mathrm{mg} / \mathrm{kg}$ dose was indeed the dose resulting in the maximal effect on operant responding.

In experiment $1 \mathrm{~B}$ sibutramine decreased responding for sucrose pellets [Fig. $1 ; \chi^{2}(3)=12.1, P=0.006$ ], but this effect was only significant at a dose of $1 \mathrm{mg} / \mathrm{kg}(Z=$ $-2.53, P=0.01$; Fig. 1$)$. Responding on the inactive lever presses was not significantly affected by either sibutramine or olanzapine (data not shown).

When olanzapine $(0.1 \mathrm{mg} / \mathrm{kg})$ was followed by administration of the subeffective dose of sibutramine $(0.3 \mathrm{mg} / \mathrm{kg})$ in experiment $1 \mathrm{C}$, it no longer affected breakpoint compared with control injections $(Z=-1.30, P=0.21$; Fig. 1$)$.

\section{Experiment 2}

In this pilot experiment, in which rats lever-pressed for fat-enriched pellets instead of sucrose pellets, the doseresponse curve of olanzapine exhibited an inverted-U shape, with a maximum effect observed at the $0.1 \mathrm{mg} / \mathrm{kg}$ dose (average increase of 1.1 rewards \pm 0.8 ). Although the effect failed to reach significance because of the limited number of animals $\left[\chi^{2}(3)=4.24, P=0.2\right]$, the shape of the dose-response curve of olanzapine was remarkably

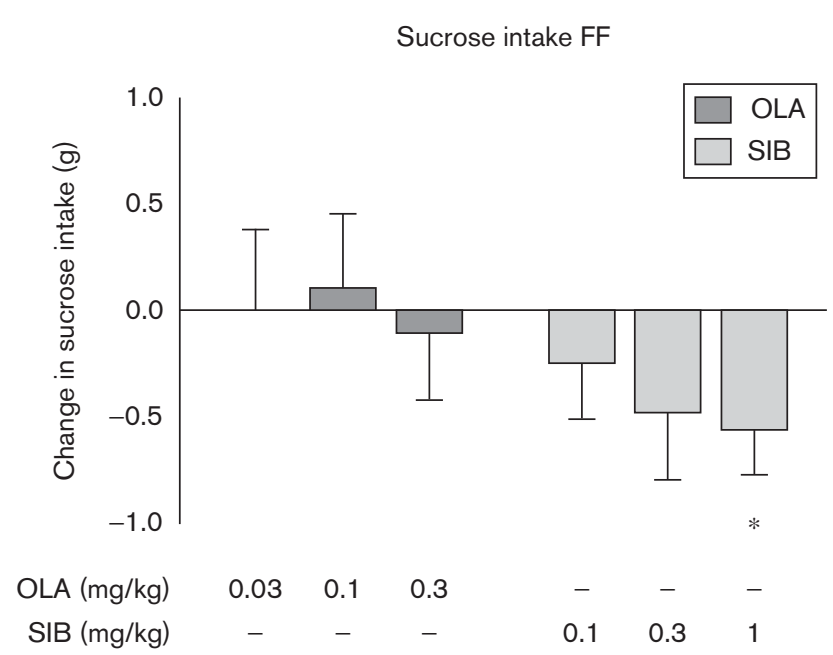

Effects of olanzapine (OLA) and sibutramine (SIB) on free feeding of sucrose pellets in experiment 3 . Data are expressed as change in sucrose intake compared with control injection (mean \pm SEM). $* P=0.015$.

similar to that observed for sucrose pellets in experiment 1A (data not shown). Because the effect on operant responding for fat-enriched pellets in this pilot experiment was also of comparable magnitude, only sucrose pellets were used for the rest of the study.

\section{Experiment 3}

In experiment $3 \mathrm{~A}$, free-feeding intake of sucrose pellets after saline injection was $4.0 \pm 0.4 \mathrm{~g}$. Administration of olanzapine failed to show any significant effects (Fig. 2). In experiment $3 \mathrm{~B}$, sucrose intake after saline injection was $5.3 \pm 0.4 \mathrm{~g}$. Sibutramine dose-dependently reduced the intake of sucrose pellets $\left[\chi^{2}(3)=12.3, P<0.01\right]$. As in experiment $1 \mathrm{~B}$, this effect was only significant for the $1 \mathrm{mg} / \mathrm{kg}$ dose $(Z=-2.51, P=0.03)$. Because olanzapine failed to show any effect in this paradigm we did not investigate the effects of combined administration.

\section{Discussion}

In this study, we investigated the effects of the secondgeneration antipsychotic drug olanzapine and the weightloss drug sibutramine on the motivation to work for palatable food in male rats. We found that olanzapine increased operant responding for sucrose pellets under a PR schedule of reinforcement, whereas sibutramine dosedependently reduced operant responding, indicating an opposite effect of these two drugs on the motivation to work for palatable food. With combined administration, the effect of olanzapine on operant responding was counteracted by a dose of sibutramine that failed to affect motivation significantly when administered alone, which suggests that both drugs affect motivation for palatable food through interacting mechanisms. 
It has been shown previously that rats increase their motivation to work for food when they are food restricted, if the palatability of the food is increased, and after administration of certain drugs such as opioids (Hodos, 1961; Solinas and Goldberg, 2005). In these cases, intake of food is also increased under conditions in which animals are not required to perform any demanding tasks to obtain it (Kelley et al., 2002; Barbano et al., 2009). In contrast, certain pharmacological manipulations selectively affect the motivation to perform a demanding task to earn a food reward, without any effects on the intake of freely available food - for example, dopamine depletion in the nucleus accumbens (Salamone and Correa, 2002). Thus, drug effects on motivation for food and on freefeeding intake can occur through overlapping but distinct neural and behavioral mechanisms. We previously found that olanzapine increases chow intake only after acute administration of doses of $0.3 \mathrm{mg} / \mathrm{kg}$ or higher (E.M. van der Zwaal, S.E. La Fleur, R.A.H. Adan et al., unpublished data). In the present study, however, a lower dose of $0.1 \mathrm{mg} / \mathrm{kg}$ increased motivation for sucrose. Moreover, we failed to observe an effect on free-feeding intake of sucrose. Taken together, this implies that olanzapine, at low doses, selectively affects the motivation to work for palatable food.

The lack of effect on free-feeding intake of sucrose argues against an effect of olanzapine on the perceived palatability of the sucrose pellets. This is in line with our previous finding that olanzapine did not affect the intake of a sucrose solution when rats were offered a diet choice in their home cage (van der Zwaal et al., 2010). It is also consistent with two clinical studies that failed to observe any difference in food choice in patients treated with second-generation antipsychotics (Gothelf et al., 2002; Henderson et al., 2006). Therefore, olanzapine-treated patients may not have increased preference for palatable foods; yet, when they do experience a desire for these foods, they are more likely to perceive it as 'craving' and willing to put in more effort to fulfill their desire. The subsequent increase in (high calorie) food intake may be one of the pathways through which olanzapine induces weight gain, although it appears that additional mechanisms also play a role (Cooper et al., 2007; van der Zwaal et al., 2010).

Contrary to olanzapine, sibutramine caused a decrease in breakpoint when rats responded for sucrose under a PR schedule, indicating a reduction in motivation for sucrose. However, under free-feeding conditions, sibutramine also significantly reduced intake of sucrose pellets, which suggests that the effect of sibutramine on motivation may have been secondary to effects on perceived palatability or satiation. Previous studies in rats indicate that sibutramine does not affect regular food intake at doses lower than $2 \mathrm{mg} / \mathrm{kg}$ (Jackson et al., 1997; Grignaschi et al., 1999); yet, in the present study we already observed an effect on sucrose intake at a dose of $1 \mathrm{mg} / \mathrm{kg}$. Similarly, a number of other studies that offered food that was more palatable than standard laboratory chow also reported reductions in food intake after administering doses of sibutramine that were lower than $2 \mathrm{mg} / \mathrm{kg}$ (Cifani et al., 2009; Tallett et al., 2009; Pratt and Connolly 2010; Higgs et al., 2011). Taken together, these findings suggest that sibutramine affects palatable feeding at doses that are lower than those that affect regular food intake. Additional studies would be necessary to confirm whether sibutramine may affect the perceived palatability of food independently of effects on satiety - for example, observation of hedonic reactions (Berridge and Kringelbach, 2008).

After combined administration, a low dose of sibutramine $(0.3 \mathrm{mg} / \mathrm{kg})$, which failed to affect operant responding or free-feeding intake of sucrose when administered alone, was able to prevent the increase in breakpoint observed after olanzapine administration $(0.1 \mathrm{mg} / \mathrm{kg})$. Although it is not possible to fully exclude effects of treatment history on the data of the present study, the lack of effect of olanzapine on breakpoint when combined with administration of a subeffective dose of sibutramine suggests that antagonism of olanzapine at NA and/or 5-HT receptors (Bymaster et al., 1999) may be involved in its effect on motivation for sucrose. Similar to sibutramine, the 5-HT releaser fenfluramine and the 5-HT reuptake inhibitor fluoxetine have been shown to reduce operant responding for palatable food in sated animals (Evenden and Ko, 2007; Sanders et al., 2007), and there are studies suggesting that the $5-\mathrm{HT}_{2 \mathrm{C}}$ receptor plays a role in this effect (Ward et al., 2008; Higgs et al., 2011). Similarly, the NA reuptake inhibitor thionisoxetine reduces free-feeding intake of palatable food (Rowland et al., 2000), although, to our knowledge, the role of specific NA receptor subtypes in the motivation for palatable food has not been investigated. Investigation of transporter occupancy after administration of sibutramine to rats previously showed that, at a dose of $1 \mathrm{mg} / \mathrm{kg}$, occupancy of NA transporters was $\sim 35 \%$, whereas that of 5-HT transporters was only $3 \%$ (Thomas et al., 2009). Thus, NA receptors are more likely than 5-HT receptors to be involved in the effects of olanzapine and sibutramine on food motivation observed in the present study (Bymaster et al., 1996).

Considering the inverted-U shape of the olanzapine doseresponse curve, it is relevant to ask whether the attenuation of the effect of the effective dose of olanzapine by sibutramine in this study could be due to potentiation of this dose by sibutramine (e.g. by increasing plasma levels or enhancing the sedative effects of olanzapine). However, previous data from our laboratory showed that sibutramine did not enhance the effect of olanzapine on observed locomotor activity (S.K. Janhunen, S.E. La Fleur, R.A.H. Adan, unpublished). Furthermore, therapeutic doses of sibutramine failed to alter the pharmacokinetic properties of therapeutic doses of olanzapine in a 10-day study in humans (wrwe.rxabbott.com/pdf/meridia.pdf), making a pharmacokinetic 
interaction less likely, especially at the low doses used in the present study. Nevertheless, further studies are necessary to confirm whether NA and/or 5-HT receptors play a role in the effect of olanzapine on food motivation.

Although olanzapine administration caused a significant increase in responding for sucrose, this effect was only significant at the dose of $0.1 \mathrm{mg} / \mathrm{kg}$. Doses that were both higher and lower than $0.1 \mathrm{mg} / \mathrm{kg}$ failed to increase breakpoint significantly, whereas we observed a marked decrease in breakpoint when a dose of $3 \mathrm{mg} / \mathrm{kg}$ was administered (data not shown). A similar pattern was observed in the pilot experiment using fat-enriched pellets instead of sucrose pellets and also in a study using marmosets that reported an increase in operant responding (PR schedule) for banana milkshake at a dose of $0.05 \mathrm{mg} / \mathrm{kg}$ olanzapine, but not at higher or lower doses (Cilia et al., 2001). Therefore, the dose-response curve of olanzapine in this paradigm appears to have an 'inverted-U' shape. A similar curve has also been described previously for the effects of olanzapine on food intake (Cooper et al., 2005), as well as for the effect of clozapine (a second-generation antipsychotic closely related to olanzapine) on the motivation for milkshake and sucrose (Cilia et al., 2001; Zhang et al., 2005b; Galistu et al., 2011).

In previous experiments, we observed reduced locomotor activity for more than $2 \mathrm{~h}$ after acute administration of doses of olanzapine of $0.3 \mathrm{mg} / \mathrm{kg}$ or higher (E.M. van der Zwaal, S.E. La Fleur, R.A.H. Adan, unpublished data), most likely because of sedative side-effects for which rats appear very sensitive (Ahnaou et al., 2003). We therefore believe that at higher doses the ability to make the number of required responses within the available time may be compromised because of sedation. This possibility has been previously suggested by researchers who administered olanzapine to female rats responding for a sucrose reinforcer (Zhang et al., 2005a). Although they failed to observe an increase in breakpoint at doses varying from 0.25 to $1 \mathrm{mg} / \mathrm{kg}$, their mathematical model used to analyze lever-pressing speed indicated that administration of olanzapine enhanced the efficacy of the reinforcer, and that it also reduced motor capacity, which limited the effects on breakpoint (for details on this mathematical model see Zhang et al., 2005a). Therefore, in the paradigm used in the present study, a dose of $0.1 \mathrm{mg} / \mathrm{kg}$ olanzapine appears high enough to increase motivation for palatable food but low enough to prevent confounding of this effect by sedation.

In summary, this study shows that olanzapine and sibutramine have opposing effects on the motivation of rats to work for palatable food. Moreover, a low dose of sibutramine was able to counteract the effect of olanzapine, suggesting involvement of NA and/or 5-HT receptors in this effect. As alterations in motivation to work for palatable food may significantly influence total caloric intake, this mechanism is likely to contribute to the weight gain induced by olanzapine and to the weight-reducing effects of sibutramine.

\section{Acknowledgements}

The technical assistance by L. Jonkers, T. Oostendorp, Y.K. Lam, and Y. Revsin is gratefully acknowledged.

\section{Conflicts of interest}

This research was performed within the framework of project T2-105 of the Dutch Top Institute Pharma.

\section{References}

Ahnaou A, Megens AA, Drinkenburg WH (2003). The atypical antipsychotics risperidone, clozapine and olanzapine differ regarding their sedative potency in rats. Neuropsychobiology 48:47-54.

Barbano MF, Le Saux M, Cador M (2009). Involvement of dopamine and opioids in the motivation to eat: influence of palatability, homeostatic state, and behavioral paradigms. Psychopharmacology (Berl) 203:475-487.

Basson BR, Kinon BJ, Taylor CC, Szymanski KA, Gilmore JA, Tollefson GD (2001). Factors influencing acute weight change in patients with schizophrenia treated with olanzapine, haloperidol, or risperidone. J Clin Psychiatry 62:231-238.

Berridge KC, Kringelbach ML (2008). Affective neuroscience of pleasure: reward in humans and animals. Psychopharmacology (Berl) 199:457-480.

Blaustein JD, Wade GN (1976). Ovarian influences on the meal patterns of female rats. Physiol Behav 17:201-208.

Blouin M, Tremblay A, Jalbert ME, Venables H, Bouchard RH, Roy MA, Almeras N (2008). Adiposity and eating behaviors in patients under second generation antipsychotics. Obesity (Silver Spring) 16:1780-1787.

Boyda HN, Tse L, Procyshyn RM, Honer WG, Barr AM (2010). Preclinical models of antipsychotic drug-induced metabolic side effects. Trends Pharmacol Sci 31:484-497.

Bromel T, Blum WF, Ziegler A, Schulz E, Bender M, Fleischhaker C, et al. (1998). Serum leptin levels increase rapidly after initiation of clozapine therapy. Mol Psychiatry 3:76-80.

Bymaster FP, Calligaro DO, Falcone JF, Marsh RD, Moore NA, Tye NC, et al. (1996). Radioreceptor binding profile of the atypical antipsychotic olanzapine. Neuropsychopharmacology 14:87-96.

Bymaster FP, Nelson DL, DeLapp NW, Falcone JF, Eckols K, Truex LL, et al. (1999). Antagonism by olanzapine of dopamine D1, serotonin2, muscarinic, histamine $\mathrm{H} 1$ and alpha 1-adrenergic receptors in vitro. Schizophr Res 37:107-122.

Chapelot D, Marmonier C, Thomas F, Hanotin C (2000). Modalities of the food intake-reducing effect of sibutramine in humans. Physiol Behav 68: 299-308.

Cifani C, Polidori C, Melotto S, Ciccocioppo R, Massi M (2009). A preclinical model of binge eating elicited by yo-yo dieting and stressful exposure to food: effect of sibutramine, fluoxetine, topiramate, and midazolam. Psychopharmacology (Berl) 204:113-125.

Cilia J, Piper DC, Upton N, Hagan JJ (2001). Clozapine enhances breakpoint in common marmosets responding on a progressive ratio schedule. Psychopharmacology (Berl) 155:135-143.

Cooper GD, Pickavance LC, Wilding JP, Halford JC, Goudie AJ (2005). A parametric analysis of olanzapine-induced weight gain in female rats. Psychopharmacology (Berl) 181:80-89.

Cooper GD, Pickavance LC, Wilding JP, Harrold JA, Halford JC, Goudie AJ (2007). Effects of olanzapine in male rats: enhanced adiposity in the absence of hyperphagia, weight gain or metabolic abnormalities. J Psychopharmacol 21:405-413.

Costa e Silva JA, Alvarez N, Mazzotti G, Gattaz WF, Ospina J, Larach V, et al. (2001). Olanzapine as alternative therapy for patients with haloperidolinduced extrapyramidal symptoms: results of a multicenter, collaborative trial in Latin America. J Clin Psychopharmacol 21:375-381.

Eder U, Mangweth B, Ebenbichler C, Weiss E, Hofer A, Hummer M, et al. (2001). Association of olanzapine-induced weight gain with an increase in body fat. Am J Psychiatry 158:1719-1722.

Evenden J, Ko T (2007). The effects of anorexic drugs on free-fed rats responding under a second-order FI15-min (FR10:S) schedule for high incentive foods. Behav Pharmacol 18:61-69.

Galistu A, Modde C, Pireddu MC, Franconi F, Serra G, D'Aquila PS (2011). Clozapine increases reward evaluation but not overall ingestive behaviour in rats licking for sucrose. Psychopharmacology (Berl) 216:411-420.

Gothelf D, Falk B, Singer P, Kairi M, Phillip M, Zigel L, et al. (2002). Weight gain associated with increased food intake and low habitual activity levels in male adolescent schizophrenic inpatients treated with olanzapine. Am J Psychiatry 159:1055-1057 
Grignaschi G, Fanelli E, Scagnol I, Samanin R (1999). Studies on the role of serotonin receptor subtypes in the effect of sibutramine in various feeding paradigms in rats. Br J Pharmacol 127:1190-1194.

Halford JC, Boyland EJ, Cooper SJ, Dovey TM, Huda MS, Dourish CT, et al. (2010). The effects of sibutramine on the microstructure of eating behaviour and energy expenditure in obese women. J Psychopharmacol 24:99-109.

Henderson DC, Copeland PM, Daley TB, Borba CP, Cather C, Nguyen DD, et al. (2005). A double-blind, placebo-controlled trial of sibutramine for olanzapineassociated weight gain. Am J Psychiatry 162:954-962.

Henderson DC, Borba CP, Daley TB, Boxill R, Nguyen DD, Culhane MA, et al. (2006). Dietary intake profile of patients with schizophrenia. Ann Clin Psychiatry 18:99-105.

Higgs S, Cooper AJ, Barnes NM (2011). Reversal of sibutramine-induced anorexia with a selective $5-\mathrm{HT}(2 \mathrm{C})$ receptor antagonist. Psychopharmacology (Berl) 214:941-947.

Hodos W (1961). Progressive ratio as a measure of reward strength. Science 134:943-944.

Jackson HC, Needham AM, Hutchins LJ, Mazurkiewicz SE, Heal DJ (1997). Comparison of the effects of sibutramine and other monoamine reuptake inhibitors on food intake in the rat. Br J Pharmacol 121:1758-1762.

Kelley AE, Bakshi VP, Haber SN, Steininger TL, Will MJ, Zhang M (2002). Opioid modulation of taste hedonics within the ventral striatum. Physiol Behav 76:365-377.

Kluge M, Schuld A, Himmerich H, Dalal M, Schacht A, Wehmeier PM, et al. (2007). Clozapine and olanzapine are associated with food craving and binge eating: results from a randomized double-blind study. J Clin Psychopharmaco/ 27:662-666.

La Fleur SE, Vanderschuren LJ, Luijendijk MC, Kloeze BM, Tiesjema B, Adan RA (2007). A reciprocal interaction between food-motivated behavior and dietinduced obesity. Int J Obes (Lond) 31:1286-1294

Leucht S, Corves C, Arbter D, Engel RR, Li C, Davis JM (2009a). Secondgeneration versus first-generation antipsychotic drugs for schizophrenia: a meta-analysis. Lancet 373:31-41.

Leucht S, Komossa K, Rummel-Kluge C, Corves C, Hunger H, Schmid F, et al. (2009b). A meta-analysis of head-to-head comparisons of second-generation antipsychotics in the treatment of schizophrenia. Am J Psychiatry 166:152-163.

Luque CA, Rey JA (2002). The discovery and status of sibutramine as an anti-obesity drug. Eur J Pharmacol 440:119-128.

Malone M (2005). Medications associated with weight gain. Ann Pharmacother 39:2046-2055.

McElroy SL, Frye MA, Altshuler LL, Suppes T, Hellemann G, Black D, et al. (2007). A 24-week, randomized, controlled trial of adjunctive sibutramine versus topiramate in the treatment of weight gain in overweight or obese patients with bipolar disorders. Bipolar Disord 9:426-434.

Parsons B, Allison DB, Loebel A, Williams K, Giller E, Romano S, Siu C (2009). Weight effects associated with antipsychotics: A comprehensive database analysis. Schizophr Res 110:103-110.

Pratt WE, Connolly ME (2010). Contrasting effects of systemic and central sibutramine administration on the intake of a palatable diet in the rat. Neurosci Lett 481:30-34.

Richardson NR, Roberts DC (1996). Progressive ratio schedules in drug selfadministration studies in rats: a method to evaluate reinforcing efficacy. J Neurosci Methods 66:1-11.
Roberts DC, Bennett SA (1993). Heroin self-administration in rats under a progressive ratio schedule of reinforcement. Psychopharmacology (Berl) 111:215-218.

Rowland NE, Marshall M, Roth JD (2000). Comparison of either norepinephrineuptake inhibitors or phentermine combined with serotonergic agents on food intake in rats. Psychopharmacology (Berl) 149:77-83.

Salamone JD, Correa M (2002). Motivational views of reinforcement: implications for understanding the behavioral functions of nucleus accumbens dopamine. Behav Brain Res 137:3-25.

Sanders AC, Hussain AJ, Hen R, Zhuang X (2007). Chronic blockade or constitutive deletion of the serotonin transporter reduces operant responding for food reward. Neuropsychopharmacology 32:2321-2329.

Scherk H, Pajonk FG, Leucht S (2007). Second-generation antipsychotic agents in the treatment of acute mania: a systematic review and meta-analysis of randomized controlled trials. Arch Gen Psychiatry 64: 442-455.

Smith LA, Cornelius V, Warnock A, Bell A, Young AH (2007). Effectiveness of mood stabilizers and antipsychotics in the maintenance phase of bipolar disorder: a systematic review of randomized controlled trials. Bipolar Disord 9:394-412.

Solinas M, Goldberg SR (2005). Motivational effects of cannabinoids and opioids on food reinforcement depend on simultaneous activation of cannabinoid and opioid systems. Neuropsychopharmacology 30:2035-2045.

Stauffer VL, Lipkovich I, Hoffmann VP, Heinloth AN, McGregor HS, Kinon BJ (2009). Predictors and correlates for weight changes in patients co-treated with olanzapine and weight mitigating agents; a post-hoc analysis. BMC Psychiatry 9:12.

Tallett AJ, Blundell JE, Rodgers RJ (2009). Sibutramine-induced anorexia: potent dose-dependent and behaviourally-selective profile in male rats. Behav Brain Res 198:359-365.

Ter Haar MB (1972). Circadian and estrual rhythms in food intake in the rat. Horm Behav 3:213-219.

Thomas GH, Babbs AJ, Chatfield RE, Krulle TM, Widdowson PS, Provost D McCormack JG (2009). 5-HT(1A) activation counteracts cardiovascular but not hypophagic effects of sibutramine in rats. Obesity (Silver Spring) 17:467-473.

van der Zwaal EM, Luijendijk MC, Evers SS, la Fleur SE, Adan RA (2010). Olanzapine affects locomotor activity and meal size in male rats. Pharmacol Biochem Behav 97:130-137.

Ward SJ, Lefever TW, Jackson C, Tallarida RJ, Walker EA (2008). Effects of a Cannabinoid1 receptor antagonist and Serotonin2C receptor agonist alone and in combination on motivation for palatable food: a dose-addition analysis study in mice. J Pharmacol Exp Ther 325:567-576.

Zhang Z, Rickard JF, Asgari K, Body S, Bradshaw CM, Szabadi E (2005a) Quantitative analysis of the effects of some 'atypical' and 'conventional' antipsychotics on progressive ratio schedule performance. Psychopharmacology (Berl) 179:489-497.

Zhang Z, Rickard JF, Body S, Asgari K, Bradshaw CM, Szabadi E (2005b). Comparison of the effects of clozapine and 8-hydroxy-2-(di-n-propylamino)tetralin (8-OH-DPAT) on progressive ratio schedule performance: evidence against the involvement of 5-HT1A receptors in the behavioural effects of clozapine. Psychopharmacology (Berl) 181:381-391. 